\title{
Association Between Body Mass Index, Its Change And Cognitive Impairment Among Chinese Older Adults: A Community-Based, 9-Year Prospective Cohort Study
}

\section{Shanshan Wu}

Capital Medical University

Xiaozhen Lv

Peking University Institute of Mental Health: Peking University Sixth Hospital

Jie Shen ( $\nabla$ shenjie_96@163.com )

Zhejiang University - School of Medicine - School of Public Health

Hui Chen

Zhejiang University - School of Medicine - School of Public Health

\section{Yuan Ma}

Harvard University T H Chan School of Public Health

Xurui Jin

MindRank Al ltd.

\section{Jiaxi Yang}

Harvard University T H Chan School of Public Health

\section{Yaying Cao}

Shanghai Institutes of Nutrition and Health CAS: Chinese Academy of Sciences Shanghai Institutes of Nutrition and Health

\section{Geng Zong}

Chinese Academy of Sciences Shanghai Institutes of Nutrition and Health

\section{Huali Wang}

Peking University Institute of Mental Health: Peking University Sixth Hospital

\section{Changzheng Yuan}

Zhejiang University - School of Medicine - School of Public Health

\section{Research Article}

Keywords: BMI, BMI change, cognitive impairment, older adults, Chinese, cohort

Posted Date: April 26th, 2021

DOI: https://doi.org/10.21203/rs.3.rs-417270/v1 
License: (우 (i) This work is licensed under a Creative Commons Attribution 4.0 International License. Read Full License

Version of Record: A version of this preprint was published at European Journal of Epidemiology on August 9th, 2021. See the published version at https://doi.org/10.1007/s10654-021-00792-y. 


\section{Abstract}

Objective To examine the association of baseline body mass index (BMI) and BMI change with cognitive impairment among older adults in China.

Methods The study included data from the Chinese Longitudinal Healthy Longevity Study, a national community-based prospective cohort study from 2002-2018. Baseline BMI and BMI change measurements were available for 12,027 adults aged older than 65 years. Cognitive impairment was defined as Chinese version of the Mini Mental State Examination score less than 18. Multivariable Cox proportional hazard model was used.

Results Among 12027 participants (mean age was 81.23 years old and $47.48 \%$ were male), the proportion of underweight, normal, overweight and obese at baseline was $33.87 \%, 51.39 \%, 11.39 \%$ and $3.34 \%$, respectively. During an average of 5.9 years' follow-up, 3086 participants ( 4.35 per 100 person-years) with incident cognitive impairment were identified. Compared with normal weight group, adjusted hazard ratio (AHR) for cognitive impairment was 0.86 (95\% Cl 0.75-0.99) among overweight group, whereas corresponding AHR was 1.02 (95\% $\mathrm{Cl} 0.94-1.10)$ in underweight and 1.01 (95\% $\mathrm{Cl} 0.80-1.28)$ in obese. Large weight loss (<-10\%) was significantly associated with an increased risk of cognitive impairment (AHR, 1.42, $95 \% \mathrm{Cl} 1.29-1.56)$, compared to stable weight status group (-5\% 5\%). In the restricted cubic spline models, BMI change showed a L-shaped association with cognitive impairment.

Conclusions BMI-defined overweight is associated with a reduced risk of cognitive impairment among Chinese older adults, while large weight loss is associated with increased risk. More attention should be paid to older adults with significant weight loss.

\section{Introduction}

With the rapid growing of elderly population, cognitive impairment and dementia have become a major public health concern worldwide, particularly in China[1]. Epidemiological studies estimated the prevalence of mild cognitive impairment as $15.5 \%$ among Chinese elderly over 60 years old, representing approximately 38 million cases[2]. Currently, there is limited effective therapy on dementia, the critical prognosis of cognitive impairment. Therefore, it is critically important to identify the potential risk factors associated with cognitive impairment, particularly modifiable risk factors, to prevent or delay cognitive impairment effectively.

Given the high prevalence of obesity, measured by body mass index (BMI), and its biological plausibility, increasing attention is being paid to investigate its relationship with cognitive impairment in older adults. However, the results are paradoxical. Some studies reported higher BMI associated with poor cognitive function in late life[1, 3, 4], whereas others[5-7] reported the protective effect of higher BMI on cognitive function. Discrepancies may be partly explained by differences in sample size, age distributions (mean age $<70$ years old or above), and follow-up time ( $<5$ years or more). Also, limited studies have adopted prospective methods on this topic among Chinese elderly population, despite some cross-sectional 
studies[6, 8]. To our knowledge, the association between BMI status and cognitive impairment has not been thoroughly evaluated among a national cohort of Chinese older adults.

Besides static weight status, among older individuals, weight changes often reflect declines in muscle mass and bone density[9], whereas few studies investigated the relationship between elderly weight/BMI change and cognitive impairment[7, 10, 11]. Also, limited period of follow up and suboptimal selection of weight loss measures hindered these studies from reflecting the long-term prospective relationship. Therefore, the aim of our study was to examine the association between $\mathrm{BMI}$ and its change with cognitive impairment based on Chinese Longitudinal Healthy Longevity Study (CLHLS), a national community-based prospective cohort of oldest adults in China with long-term follow up.

\section{Materials And Methods}

\section{Study population}

This study is based on the Chinese Longitudinal Healthy Longevity Study (CLHLS), which is an ongoing, prospective cohort study of community-dwelling Chinese older people from 1998, covering approximately $85 \%$ of China's population with representative data to investigate determinants of longevity[12-14]. New participants are enrolled during every 2-4 years of follow-up in order to reduce the attrition due to death and loss to follow-up. The surveys are conducted through face-to-face interviews in participants' homes by trained interviewers with a structured questionnaire. Each interviewer was accompanied by a local doctor, a nurse, or a medical college student. All participants or their proxy respondents signed written consent forms to participate in the baseline and follow-up surveys. The study was approved by the Biomedical Ethics Committee of Peking University (IRB00001052-13074).

The present study was based on three successive 9 to 10-year cohorts (the 2002-2011, 2005-2014 and 2008-2018 cohorts) within the CLHLS. Four waves were performed in each cohort (2002, 2005, 2008 and 2011 in the 2002-2011 cohort; 2005, 2008, 2011 and 2014 in the 2005-2014 cohort; and 2008, 2011, 2014 and 2018 in the 2008-2018 cohort). Participants who were with normal cognition (score $\geq 18$ on the Chinese version of Mini-Mental State Examination, MMSE) at baseline and completed at least once cognitive function assessments during follow-up surveys were included as study population. Participants were excluded due to poor cognitive function at baseline (MMSE score<18), a history of stroke or dementia at baseline, without baseline BMI or weight at the first follow-up, dead during the first year and lost to followup at the first 3-year survey. For participants who were enrolled in two or more cohorts, we only chose the record with the longest follow-up period. After excluding 5402 duplicated participants in three cohorts, a total of 12,027 participants were included in the final analysis, with 5285 from the 2002-2011 cohort, 2088 from the 2005-2014 cohort and 4654 from the 2008-2018 cohort (Figure 1).

\section{Measurement of baseline BMI and BMI change}

Body weight and height were measured by trained medical staff according to the standardized protocol. Body weight was measured when individuals wearing light clothing in each wave. Height was measured as knee height (vertical distance from sole of the foot to the upper surface of the knee, with knee and ankle 
each flexed to a $90^{\circ}$ angle) in 2002 wave, and direct height in 2005 and 2008 waves. A validated equation[15] was used to calculate height at baseline for participants in 2002-2011 cohort (men, height $=67.78+2.01 *$ knee height; women, height $=74.08+1.81 *$ knee height).

Baseline BMI was classified into 4 categories according to the guideline for Chinese[16], including underweight (BMI $\left.<18.5 \mathrm{~kg} / \mathrm{m}^{2}\right)$, normal weight $\left(18.5 \leq \mathrm{BMI}<23.9 \mathrm{~kg} / \mathrm{m}^{2}\right)$, overweight $(24 \leq \mathrm{BMI}<27.9$ $\mathrm{kg} / \mathrm{m}^{2}$ ) and obese $\left(\mathrm{BMI} \geq 28 \mathrm{~kg} / \mathrm{m}^{2}\right)$. BMI change during the first-3 year was calculated through the difference between BMI at the third year and baseline BMI divided by baseline BMI, and classified into 5 groups, including large weight loss (BMI change $<-10 \%)$, small weight loss $(-10 \% \leq \mathrm{BMI}$ change $<-5 \%)$, stable weight status $(-5 \% \leq \mathrm{BMl}$ change $<5 \%)$, small weight gain $(5 \% \leq \mathrm{BMl}$ change $<10 \%)$ and large weight gain (BMl change $>10 \%)$.

\section{Assessment of cognitive function}

Cognitive function was measured by the Chinese version of MMSE scale during each survey through a homebased interview. The validity and reliability of the Chinese MMSE has been verified in several studies[12, 13, 17]. Based on the literature[18, 19], we considered responses of "unable to answer" as"wrong". The MMSE score ranged from 0 to 30, with a higher score indicating better cognitive function. Since $54.9 \%$ of participants in the cohort were illiterate, a relatively low cutoff with MMSE score less than 18 was defined as cognitive impairment[20].

\section{Covariates}

Sociodemographic characteristics, health behaviors and diet habits at baseline were adjusted as covariates in the model, which was selected as a prior based on the literature[18, 20]. Potential confounders included age (as a continuous variable), sex (male or female), type of residence (urban or rural), marital status (married or not), education (illiterate, defined as receiving $<1$ year of any formal education; literate, defined as receiving $\geq 1$ year of any formal education), living arrangement (with family member or alone/in nursing home), smoking status (never smoking, current smoking, former smoking), drinking status(never drinking, current drinking, former drinking), regular exercise (yes or no), vegetables intake (always, defined as eat vegetables almost every day; not always, defined as eat vegetables except winter, occasionally, or rarely/never) and fruit intake (always, defined as eat fruit almost every day; not always, defined as eat fruit except winter, occasionally, or rarely/never).

\section{Statistical analysis}

Cox proportional hazard model was performed to investigate the association of baseline BMI and BMI change with cognitive impairment. The endpoint was the first occurrence of cognitive impairment. The follow-up period started from baseline to the date of the first occurrence of cognitive impairment, or censored at the end of the study (the fourth wave), the date of death or lost-to-follow-up for those participants who did not develop cognitive impairment. Considering the very small percentage of missing values for covariates $(0.017 \%$ of fruit consuming and $0.042 \%$ of vegetable consuming variables were missing), missing indicators were used to handle the analysis. Proportional hazard assumption was 
ascertained and satisfied by Kaplan-Meier curves for categorized variables and testing linear regression of scaled Schoenfeld residuals on functions of time for continuous variables.

For both baseline BMI and BMI change, the adjustment was accomplished via three models: (1) model 1 , univariable analysis; (2) model 2, adjusted for age and sex; (3) model 3, additionally adjusted type of residence, marital status, education, living arrangement, smoking status, drinking status, regular exercise, vegetables and fruit intake. For the association of BMI change and cognitive impairment, baseline BMI was additionally adjusted in model 3 . Moreover, restricted cubic spline analysis was conducted to examine the shape of the association of baseline BMI and BMI change with cognitive impairment after adjusting covariates in model 3 , respectively, with knots placed at 10th, 50th and 90th percentiles and median value of baseline BMI $\left(19.84 \mathrm{~kg} / \mathrm{m}^{2}\right)$ and $\mathrm{BMI}$ change $(0 \%)$ as reference point.

Additionally, subgroup analysis was performed to investigate whether the association with baseline BMI and BMI change varied by age (65-79 years, $\geq 80$ years), sex (male, female), educational (illiterate or not), smoking status (current drinker or not), alcohol drinking status (current drinker or not), regular exercise (yes, no). Effect modification was also detected by adding interaction terms of BMI and the abovementioned variables in the multivariable model, respectively. Further stratified multivariable analysis was conducted to explore the impact of BMI change on cognitive impairment in participants with different baseline BMI level (underweight, normal, overweight and obese).

Since participants who were lost to follow-up might be more likely to develop cognitive impairment, sensitivity analysis was conducted to assess the robustness of the results by excluding participants who were lost to follow-up during the second 3 years. In addition, another sensitivity analysis was conducted by using the MMSE score less than 24 as the definition of cognitive impairment. History of multiple major chronic diseases (as at least one of the following diseases: diabetes, hypertension, heart disease and cancer) were not included in our multivariable model, because it may lie within the causal pathway of BMI and cognitive impairment. However, we also conducted sensitivity analyses after further adjustment of these variables.

A two-tailed $P$ value $<0.05$ was considered to be statistically significant. All analyses were conducted using SAS software Version 9.4 and $R$ version 4.0.2 (ggplot2 and forestplot package).

\section{Results}

\section{Participant characteristics}

Among the 12,027 participants, $47.48 \%$ were male. The mean (standard deviation, SD) age was 81.23 (10.72) years old at baseline. Approximately $55 \%$ of the participants were illiterate, and $44.93 \%$ were married. The median $(25$ th, 75 th percentile) MMSE score was $28(25,29)$ and the mean (SD) baseline BMI was $20.28(3.86) \mathrm{kg} / \mathrm{m}^{2}$ at baseline. The proportion of underweight, normal, overweight and obese at baseline was $33.87 \%, 51.40 \%, 11.39 \%$ and $3.34 \%$, respectively. As shown in Table 1, the participants with underweight were more likely to be older, be female, live in rural, be illiterate, be not married, live alone or in nursing home, have less regular exercise, and not always consuming vegetables or fruits. 
The average (SD) length of follow-up period was 5.9 (2.8) years (range, 2.1-11.2 years). A total of 3086 $(25.7 \%)$ of 12,027 participants with cognitive impairment were identified. During the 70,936 person-years of follow-up, the incidence of cognitive impairment was 4.35 per 100 person-years $(5.98,3.91,2.52$ and 3.0 per 100 person-years for those with underweight, normal, overweight, and obesity, respectively).

\section{Association of baseline BMI and BMI change with cognitive impairment}

Cox proportional hazard regression model with restricted cubic spline indicated that baseline BMI (as a continuous variable) was linearly associated with risk of cognitive impairment, with a negative and monotonic association ( $P=0.512$, Figure $2 A$ ). Table 2 showed the association of baseline BMI with cognitive impairment. Compared with normal baseline BMI group, participants with overweight showed a decreased risk of cognitive impairment (adjusted $\mathrm{HR}=0.86,95 \% \mathrm{Cl}$ : $0.75-0.99$ ) according to multivariable adjusted model, whereas those with underweight and obese both had a similar risk of cognitive impairment as those with normal baseline BMI.

\section{Association of BMl change with cognitive impairment}

The median BMI change (25th, 75th percentile) of 12,027 participants during the first 3 years was $0 \%$ $(-10.0 \%, 9.4 \%)$. The proportion of large weight loss, small weight loss, stable weight status, small weight gain and large weight gain was $24.21 \%, 12.56 \%, 29.87 \%, 9.86 \%$ and $23.50 \%$, respectively. The incidence of cognitive impairment was $6.08,3.56,3.55,3.65$ and 4.51 per 100 person-years for those with large weight loss, small weight loss, stable weight status, small weight gain and large weight gain, respectively.

According to the results of Cox proportional hazard analysis with restricted cubic spline, there was a nonlinear (U-shaped) association between BMI change and cognitive impairment $(P<0.001$, Figure 2B). Table 3 showed the association of BMI change with cognitive impairment. In comparison with participants under stable weight status during the first 3 years, participants with large weight loss were more likely to develop cognitive impairment (adjusted $\mathrm{HR}=1.42,95 \% \mathrm{Cl}$ : 1.29-1.56). No significant risk of cognitive impairment was detected in those with small weight loss, small weight gain and large weight gain compared with participants under stable weight status.

\section{Subgroup analysis}

For both baseline BMI and BMI change, similar findings were observed across age and gender subgroups (Figure 3). In particular, compared with normal BMI group, similar risk was detected for overweight participants with $65-79$ years (adjusted $\mathrm{HR}=0.89,95 \% \mathrm{Cl}: 0.67-1.17$ ) and $\geq 80$ years (adjusted $\mathrm{HR}=0.89,95 \%$ $\mathrm{Cl}$ : 0.76-1.06) (Figure 3A). As shown in Figure 3B, the adjusted HR associated with large weight loss versus stable weight status equal to 1.43 (95\% Cl: 1.13-1.81) for participants with $65-79$ years and $1.36(95 \% \mathrm{Cl}$ : 1.22-1.51) for those with $\geq 80$ years. Moreover, no significant modification was observed by age, gender, education level, major lifestyle factors and status of multiple major chronic diseases (data not shown).

Furthermore, the associations of BMI change and cognitive impairment were non-significantly different across subgroups of baseline BMI status ( $P$ for interaction $=0.388$, Table $S 1$ ). Compared with stable weight 
status, the increased risk of cognitive impairment associated with large weight loss was not only detected in participants with underweight, but also in participants with normal weight and overweight. In those participants with obese $(\mathrm{N}=402)$, large weight loss was associated with increased risk of cognitive impairment but not statistically significant, whereas significant higher risk of cognitive impairment associated with small weight gain was detected.

\section{Sensitivity analysis}

The results of sensitivity analysis were similar to the main analysis, when excluding participants who were lost to follow-up during the second 3 years, using a cutoff of MMSE score equals to 24 as the definition of cognitive impairment, or further adjustment of major chronic diseases in the multivariable model, which indicating the robustness of our results (Table S2).

\section{Discussion}

In this community-dwelling prospective cohort study, we observed a lower risk of cognitive impairment among elderly participants who were overweight, but not obese, at baseline, after adjusting for demographic and major lifestyle factors. In addition, individuals with large weight loss within a 3-year period had a greater risk of cognitive impairment compared with those in stable weight status.

The protective effect of overweight in late life in our study was consistent with several previous studies[5-7, 21-27]. A 9-year longitudinal cohort study showed overweight was associated with a $25 \%$ decreased risk of dementia versus normal weight in individuals $\geq 75$ years old[5]. Another 3 -year cohort study also reported the inverse association between baseline $\mathrm{BMI}$ and cognitive impairment in participants $\geq 65$ years old, with $3 \%$ risk reduction of cognitive impairment per $1 \mathrm{~kg} / \mathrm{m}^{2}$ increase of baseline BMI[7]. Another Korean cohort study[25] with an average of 3.7 years follow up demonstrated overweight or obese older adults showed slower cognitive decline. Similarly, a cross-sectional study conducted in 1100 Chinese individuals greater than 60 years old demonstrated a decreased risk of cognitive impairment associated with overweight with adjusted odds ratio $0.46(95 \% \mathrm{Cl}: 0.30,0.70)[6]$.

Several potential mechanisms might contribute to this protective effect of overweight in elderly participants. Firstly, it is well-known that excess body adiposity tends to accrue during early and middle adulthood for most people. Among older individuals, however, low BMI often reflect underlying illness, decline in muscle mass and bone density[10], leading to the decreased validity of BMI as a measure of adiposity among older persons $[28,29]$. Therefore, compared to older adults with lower BMI who may have worse health status, those with higher BMI may instead have a better late-life cognitive function. Secondly, some hormonal factors, such as high estrogen level in overweight elderly women secreted by extragonadal tissue[30] and leptin secreted by adipose tissue in both women and men, may play an important role in improving cognitive function[31, 32].

In terms of BMI change, the current findings suggested that large weight loss in older adults is associated with higher risk of cognitive impairment, regardless of baseline BMI, which was in line with other studies[7, $10,11]$. A 3-year follow up cohort study conducted in 5239 older participants aged over 65 years old in the 
United States also showed the risk of cognitive decline would increase $98 \%$ in participants with BMI decrease greater than 10\%[7]. Another cohort based on Women's Health Initiative Study of Cognitive Aging with average 5.4 years of follow-up also demonstrated women aged 65 to 79 years old with weight loss $\geq$ $5 \%$ had a significantly lower global cognitive function score[11]. One possible mechanism may be that sarcopenia, a syndrome with generalized loss of skeletal muscle mass and strength, which could lead to low physical activity and further contribute to cognitive decline[33-35]. In addition, a L-shape relationship between BMI change and cognitive impairment was detected in our study, suggesting that large weight loss could be associated with greater risk of cognitive impairment. However, we observed a significant higher risk of cognitive impairment associated with small weight gain among participants with obese. Considering the limited sample of obese elderly in our study, the results need to be treated with caution and confirmed in further research. In clinical practice, this finding emphasizes the importance of considering history of weight loss as a potential predictor of cognitive dysfunction among elderly patients.

A major strength of our study is the use of a well-designed, large-scaled, national representative, prospective cohort of older adults in China[12-14]. Also, the long-term and repeated follow up data allowed us to investigate the association of BMI dynamic change with cognitive impairment. Moreover, to our knowledge, this is the first study evaluating the relationship between late life BMI and its change with cognitive impairment in a national cohort of Chinese older people. Additionally, the average age of the participants in this study was 81 years old, a population with high risk of dementia, and our findings may provide crucial evidence to reduce dementia drastically. Furthermore, we conducted a variety of sensitivity analyses and verified the robustness of our results.

Our study also has limitations. Firstly, some potential covariates, either unmeasured (such as medical treatment) or unknown, may confound the association between BMI and its change with cognitive impairment owing to the observational design, although we carefully controlled for numerous potential confounders. Secondly, some confounding factors based on self-reported data, such as smoking and drinking, without accurate number of consuming cigarettes and alcohol. Thus, it may lead to recall bias although we already adjusted them in the analysis. Thirdly, the average age of our population was 81 years old, and the generalizability of our results in younger individuals needed to be further validated. Finally, the observed associations may be subject to potential reverse causation, which means that weight loss may indicate a prodromal phase of dementia.

\section{Conclusions}

Among a national representative cohort of Chinese older adults, overweight (defined as $24 \leq \mathrm{BMI}<27.9$ $\mathrm{kg} / \mathrm{m}$ ) was associated with a lower risk of cognitive impairment, while large weight loss was associated with an increased risk of cognitive impairment. These findings support a potential role for great weight loss independent of static body mass index in the development of cognitive impairment. History of body weight change is an easy-to-recall measure among elderly adults, future public health recommendation and clinical practice on body weight management should take this into consideration for the prevention of cognitive impairment among elderly adults. 


\section{Declarations}

We are grateful to all cooperating organizations and their staff in CLHLS whose hard work made this study possible. We thank the interviewees and their families for their voluntary participation in the CLHLS study.

Funding: This work was funded by the National Natural Science Foundation of China (No. 82003539 and 71490732), Capital's Funds for Health Improvement and Research (CFH2020-3-4114).

Conflicts of interests: All authors have completed the ICMJE uniform disclosure form at www.icmje.org/coi_disclosure.pdf and declare no potential conflicts of interest relevant to this article.

Data and materials availability: The CLHLS questionnaires are available at https://sites.duke.edu/centerforaging/ programs/chinese-longitudinal-healthy-longevity-surveyclhls/survey-documentation/questionnaires/. The full datasets used in this analysis are available from the corresponding author upon reasonable request.

Author Contributions: SSW, XZL and CZY designed the study. SSW and JS drafted the manuscript. SSW and $X Z L$ analyzed the data. XRJ validated the analysis. HC, YM, XZL, JXY, YYC, GZ, LHW and CZY revised the manuscript. SSW, XZL and CZY interpreted the results, incorporated comments for the co-authors and finalized the manuscript. All authors approved the final version of the paper.

Financial Disclosures: All authors have nothing to disclose.

Ethical approval and Consent to participate: The CLHLS study was approved by the Research Ethics Committee of Peking University (IRB00001052-13074), and all participants or their proxy respondents provided written informed consent.

Consent for publication: All authors are agree with the plant to submit to European Journal of Epidemiology.

\section{References}

[1] Livingston G, Sommerlad A, Orgeta V, et al. Dementia prevention, intervention, and care. Lancet. 2017;390(10113):2673-734. https://doi.org/10.1016/s0140-6736(17)31363-6

[2] Jia L, Du Y, Chu L, et al. Prevalence, risk factors, and management of dementia and mild cognitive impairment in adults aged 60 years or older in China: a cross-sectional study. Lancet Public Health. 2020;5(12):e661-e71. https://doi.org/10.1016/s2468-2667(20)30185-7

[3] Elias MF, Elias PK, Sullivan LM, Wolf PA, D'Agostino RB. Obesity, diabetes and cognitive deficit: The Framingham Heart Study. Neurobiol Aging. 2005;26 Suppl 1:11-6.

https://doi.org/10.1016/j.neurobiolaging.2005.08.019

[4] Gunstad J, Lhotsky A, Wendell CR, Ferrucci L, Zonderman AB. Longitudinal examination of obesity and cognitive function: results from the Baltimore longitudinal study of aging. Neuroepidemiology. 2010;34(4):222-9. https://doi.org/10.1159/000297742 
[5] Atti AR, Palmer K, Volpato S, Winblad B, De Ronchi D, Fratiglioni L. Late-life body mass index and dementia incidence: nine-year follow-up data from the Kungsholmen Project. J Am Geriatr Soc. 2008;56(1):111-6. https://doi.org/10.1111/j.1532-5415.2007.01458.x

[6] Hou Q, Guan Y, Yu W, et al. Associations between obesity and cognitive impairment in the Chinese elderly: an observational study. Clin Interv Aging. 2019;14:367-73. https://doi.org/10.2147/cia.S192050

[7] Rodríguez-Fernández JM, Danies E, Martínez-Ortega J, Chen WC. Cognitive Decline, Body Mass Index, and Waist Circumference in Community-Dwelling Elderly Participants. J Geriatr Psychiatry Neurol. 2017;30(2):67-76. https://doi.org/10.1177/0891988716686832

[8] Zhang T, Yan R, Chen Q, et al. Body mass index, waist-to-hip ratio and cognitive function among Chinese elderly: a cross-sectional study. BMJ Open. 2018;8(10):e022055. https://doi.org/10.1136/bmjopen-2018022055

[9] Manson JE, Bassuk SS, Hu FB, Stampfer MJ, Colditz GA, Willett WC. Estimating the number of deaths due to obesity: can the divergent findings be reconciled? J Womens Health (Larchmt). 2007;16(2):168-76. https://doi.org/10.1089/jwh.2006.0080

[10] Power BD, Alfonso H, Flicker L, Hankey GJ, Yeap BB, Almeida OP. Changes in body mass in later life and incident dementia. Int Psychogeriatr. 2013;25(3):467-78. https://doi.org/10.1017/s1041610212001834

[11] Driscoll I, Espeland MA, Wassertheil-Smoller S, et al. Weight change and cognitive function: findings from the Women's Health Initiative Study of Cognitive Aging. Obesity (Silver Spring). 2011;19(8):1595-600. https://doi.org/10.1038/oby.2011.23

[12] Lv YB, Gao X, Yin ZX, et al. Revisiting the association of blood pressure with mortality in oldest old people in China: community based, longitudinal prospective study. Bmj. 2018;361:k2158. https://doi.org/10.1136/bmj.k2158

[13] Zeng Y, Feng Q, Hesketh T, Christensen K, Vaupel JW. Survival, disabilities in activities of daily living, and physical and cognitive functioning among the oldest-old in China: a cohort study. Lancet. 2017;389(10079):1619-29. https://doi.org/10.1016/s0140-6736(17)30548-2

[14] Zeng Y. Introduction to the Chinese Longitudinal Healthy Longevity Survey (CLHLS). In: Zeng Y, Dudley LP, Denese AV, Danan G, editors. Healthy Longevity in China: demographic, socioeconomic, and psychological dimensions.: Springer, Dordrecht; 2008. p. p. 23-38.

[15] Zhang $\mathrm{H}$, Hsu-Hage $\mathrm{BH}$, Wahlqvist ML. The use of knee height to estimate maximum stature in elderly Chinese. J Nutr Health Aging. 1998;2(2):84-7.

[16] Chen C, Lu FC. The guidelines for prevention and control of overweight and obesity in Chinese adults. Biomed Environ Sci. 2004;17 Suppl:1-36. 
[17] An R, Liu GG. Cognitive impairment and mortality among the oldest-old Chinese. Int J Geriatr Psychiatry. 2016;31(12):1345-53. https://doi.org/10.1002/gps.4442

[18] Lv X, Li W, Ma Y, et al. Cognitive decline and mortality among community-dwelling Chinese older people. BMC Med. 2019;17(1):63. https://doi.org/10.1186/s12916-019-1295-8

[19] Zhang Z, Gu D, Hayward MD. Childhood nutritional deprivation and cognitive impairment among older Chinese people. Soc Sci Med. 2010;71(5):941-9. https://doi.org/10.1016/j.socscimed.2010.05.013

[20] Wang J, Li T, Lv Y, et al. Fine Particulate Matter and Poor Cognitive Function among Chinese Older Adults: Evidence from a Community-Based, 12-Year Prospective Cohort Study. Environ Health Perspect. 2020;128(6):67013. https://doi.org/10.1289/ehp5304

[21] Ghaderpanahi M, Fakhrzadeh $\mathrm{H}$, Sharifi F, et al. Association between late-life body mass index, waist circumference, and dementia: Kahrizak Elderly Study. J Am Geriatr Soc. 2012;60(1):173-4. https://doi.org/10.1111/j.1532-5415.2011.03751.x

[22] Fitzpatrick AL, Kuller LH, Lopez OL, et al. Midlife and late-life obesity and the risk of dementia: cardiovascular health study. Arch Neurol. 2009;66(3):336-42. https://doi.org/10.1001/archneurol.2008.582

[23] Suemoto CK, Gilsanz P, Mayeda ER, Glymour MM. Body mass index and cognitive function: the potential for reverse causation. Int J Obes (Lond). 2015;39(9):1383-9. https://doi.org/10.1038/ijo.2015.83

[24] Dahl AK, Löppönen M, Isoaho R, Berg S, Kivelä SL. Overweight and obesity in old age are not associated with greater dementia risk. J Am Geriatr Soc. 2008;56(12):2261-6. https://doi.org/10.1111/j.15325415.2008.01958.x

[25] Kim G, Choi S, Lyu J. Body mass index and trajectories of cognitive decline among older Korean adults. Aging Ment Health. 2020;24(5):758-64. https://doi.org/10.1080/13607863.2018.1550628

[26] Kiesswetter E, Schrader E, Diekmann R, Sieber CC, Volkert D. Varying Associations Between Body Mass Index and Physical and Cognitive Function in Three Samples of Older Adults Living in Different Settings. J Gerontol A Biol Sci Med Sci. 2015;70(10):1255-61. https://doi.org/10.1093/gerona/glv048

[27] Kim S, Kim Y, Park SM. Body Mass Index and Decline of Cognitive Function. PLoS One. 2016;11(2):e0148908. https://doi.org/10.1371/journal.pone.0148908

[28] Sullivan DH, Sun S, Walls RC. Protein-energy undernutrition among elderly hospitalized patients: a prospective study. Jama. 1999;281(21):2013-9. https://doi.org/10.1001/jama.281.21.2013

[29] Zhang J, Lyu YB, Yin ZX, Luo JS, Shi WH, Shi XM. [Follow-up study of body mass index and risk of cognitive impairment among elderly adults aged $\geq 65$ years old from longevity areas of China]. Zhonghua Yu Fang Yi Xue Za Zhi. 2017;51(11):1019-23. https://doi.org/10.3760/cma.j.issn.0253-9624.2017.11.012 
[30] Cheng D, Liang B, Hao Y, Zhou W. Estrogen receptor a gene polymorphisms and risk of Alzheimer's disease: evidence from a meta-analysis. Clin Interv Aging. 2014;9:1031-8.

https://doi.org/10.2147/cia.S65921

[31] Harvey J, Solovyova N, Irving A. Leptin and its role in hippocampal synaptic plasticity. Prog Lipid Res. 2006;45(5):369-78. https://doi.org/10.1016/j.plipres.2006.03.001

[32] Oomura Y, Hori N, Shiraishi T, et al. Leptin facilitates learning and memory performance and enhances hippocampal CA1 long-term potentiation and CaMK II phosphorylation in rats. Peptides. 2006;27(11):273849. https://doi.org/10.1016/j.peptides.2006.07.001

[33] van Dam R, Van Ancum JM, Verlaan S, Scheerman K, Meskers CGM, Maier AB. Lower Cognitive Function in Older Patients with Lower Muscle Strength and Muscle Mass. Dement Geriatr Cogn Disord. 2018;45(3-4):243-50. https://doi.org/10.1159/000486711

[34] Levine ME, Crimmins EM. Sarcopenic obesity and cognitive functioning: the mediating roles of insulin resistance and inflammation? Curr Gerontol Geriatr Res. 2012;2012:826398.

https://doi.org/10.1155/2012/826398

[35] Cruz-Jentoft AJ, Baeyens JP, Bauer JM, et al. Sarcopenia: European consensus on definition and diagnosis: Report of the European Working Group on Sarcopenia in Older People. Age Ageing. 2010;39(4):412-23. https://doi.org/10.1093/ageing/afq034

\section{Tables}

\section{Table 1. Characteristics of 12027 participants at baseline ${ }^{*}$}




\begin{tabular}{|c|c|c|c|c|c|c|}
\hline Variables & Total & Underweight & Normal & Overweight & Obese & $\begin{array}{l}P \\
\text { value }\end{array}$ \\
\hline $\begin{array}{l}\text { No. of } \\
\text { participants }\end{array}$ & $12027(100.0)$ & 4074(33.87) & 6181(51.39) & 1370(11.39) & 402(3.34) & - \\
\hline $\begin{array}{l}\text { Age, years, } \\
\text { mean (SD) }\end{array}$ & $81.23 \pm 10.72$ & $84.57 \pm 10.41$ & $80.34 \pm 10.49$ & $76.66 \pm 9.77$ & $76.59 \pm 10.35$ & $<0.001$ \\
\hline Age group & & & & & & $<0.001$ \\
\hline $65-79$ years & $5401(44.91)$ & 1274(31.27) & $2983(48.26)$ & $880(64.23)$ & $264(65.67)$ & \\
\hline$\geq 80$ years & $6626(55.09)$ & $2800(68.73)$ & $3198(51.74)$ & $490(35.77)$ & 138(34.33) & \\
\hline Sex & & & & & & $<0.001$ \\
\hline Male & $5722(47.58)$ & 1624(39.86) & $3190(51.61)$ & $720(52.55)$ & 188(46.77) & \\
\hline Female & $6305(52.42)$ & $2450(60.14)$ & 2991(48.39) & $650(47.45)$ & 214(53.23) & \\
\hline $\begin{array}{l}\text { Type of } \\
\text { residence }\end{array}$ & & & & & & $<0.001$ \\
\hline Urban & $2458(20.44)$ & $579(14.21)$ & 1299(21.02) & $443(32.34)$ & 137(34.08) & \\
\hline Rural & $9569(79.56)$ & $3495(85.79)$ & $4882(78.98)$ & $927(67.66)$ & $265(65.92)$ & \\
\hline $\begin{array}{l}\text { Marital } \\
\text { status }\end{array}$ & & & & & & $<0.001$ \\
\hline Married & $5404(44.93)$ & $1369(33.60)$ & 2986(48.31) & $817(59.64)$ & 232(57.71) & \\
\hline Not married & $6623(55.07)$ & $2705(66.40)$ & $3195(51.69)$ & $553(40.36)$ & $170(42.29)$ & \\
\hline Education & & & & & & $<0.001$ \\
\hline Illiterate & $6606(54.93)$ & $2673(65.61)$ & $3200(51.77)$ & 547(39.93) & $186(46.27)$ & \\
\hline Literate & $5421(45.07)$ & 1401(34.39) & $2981(48.23)$ & $823(60.07)$ & 216(53.73) & \\
\hline $\begin{array}{l}\text { Living } \\
\text { arrangement }\end{array}$ & & & & & & $<0.001$ \\
\hline $\begin{array}{l}\text { With family } \\
\text { member }\end{array}$ & $9982(83.00)$ & $3286(80.66)$ & $5167(83.59)$ & $1180(86.13)$ & $349(86.82)$ & \\
\hline $\begin{array}{l}\text { Alone or in } \\
\text { nursing } \\
\text { home }\end{array}$ & $2045(17.00)$ & 788(19.34) & 1014(16.41) & 190(13.87) & $53(13.18)$ & \\
\hline $\begin{array}{l}\text { Smoking } \\
\text { status }\end{array}$ & & & & & & $<0.001$ \\
\hline $\begin{array}{l}\text { Never } \\
\text { smoking }\end{array}$ & 7584(63.06) & $2730(67.01)$ & $3752(60.07)$ & $846(61.75)$ & $256(63.68)$ & \\
\hline $\begin{array}{l}\text { Current } \\
\text { smoking }\end{array}$ & $2727(22.67)$ & 833(20.45) & $1506(24.36)$ & $304(22.19)$ & $84(20.90)$ & \\
\hline
\end{tabular}




\begin{tabular}{|c|c|c|c|c|c|c|}
\hline $\begin{array}{l}\text { Former } \\
\text { smoking }\end{array}$ & $1716(14.27)$ & $511(12.54)$ & $923(14.93)$ & $220(16.06)$ & $62(15.42)$ & \\
\hline $\begin{array}{l}\text { Drinking } \\
\text { status }\end{array}$ & & & & & & $<0.001$ \\
\hline $\begin{array}{l}\text { Never } \\
\text { drinking }\end{array}$ & 7988(66.42) & $2832(69.51)$ & $4021(65.05)$ & $872(63.65)$ & $263(65.42)$ & \\
\hline $\begin{array}{l}\text { Current } \\
\text { drinking }\end{array}$ & $2753(22.89)$ & $829(20.35)$ & $1491(24.12)$ & $340(24.82)$ & $93(23.13)$ & \\
\hline $\begin{array}{l}\text { Former } \\
\text { drinking }\end{array}$ & $1286(10.69)$ & $413(10.14)$ & 669(10.82) & 158(11.53) & 46(11.44) & \\
\hline $\begin{array}{l}\text { Regular } \\
\text { exercise }\end{array}$ & & & & & & $<0.001$ \\
\hline Yes & $4342(36.10)$ & 1182(29.01) & 2326(37.63) & 647(47.23) & 187(46.52) & \\
\hline No & $7685(63.90)$ & 2892(70.99) & $3855(62.37)$ & 723(52.77) & 215(53.48) & \\
\hline $\begin{array}{l}\text { Vegetables } \\
\text { intake }\end{array}$ & & & & & & $<0.001$ \\
\hline Always & $7295(60.68)$ & $2304(56.58)$ & $3807(61.61)$ & $913(66.64)$ & 271(67.58) & \\
\hline Not always & 4727(39.32) & $1768(43.42)$ & 2372(38.39) & 457(33.36) & 130(32.42) & \\
\hline Fruits intake & & & & & & $<0.001$ \\
\hline Always & 1374(11.43) & 294(7.22) & 739(11.96) & 252(18.39) & $89(22.19)$ & \\
\hline Not always & 10651(88.57) & $3780(92.78)$ & $5441(88.04)$ & 1118(81.61) & 312(77.81) & \\
\hline $\begin{array}{l}\text { Duration of } \\
\text { follow-up, } \\
\text { months, } \\
\text { median } \\
\text { (25th, 75th } \\
\text { percentile) }\end{array}$ & 70(37-109) & $54(36-94)$ & 71(37-110) & 74(38-111) & 71(37-111) & $<0.001$ \\
\hline
\end{tabular}

Note: All participants were classified as underweight ((body mass index $\left.(\mathrm{BMI})<18.5 \mathrm{~kg} / \mathrm{m}^{2}\right)$, normal $(18.5 \leq$ $\left.\mathrm{BMI}<24.0 \mathrm{~kg} / \mathrm{m}^{2}\right)$, overweight $\left(24.0 \leq \mathrm{BMI}<28.0 \mathrm{~kg} / \mathrm{m}^{2}\right)$ and obesity $\left(\mathrm{BMI} \geq 28 \mathrm{~kg} / \mathrm{m}^{2}\right)$.

* Data are expressed as counts (percentages), except for age and duration of follow-up.

Table 2. The association between baseline BMI and the incidence of cognitive impairment 


\begin{tabular}{|c|c|c|c|c|c|}
\hline \multirow[b]{2}{*}{ Model } & \multirow[b]{2}{*}{ Categorical } & \multirow[b]{2}{*}{ Events } & \multirow[b]{2}{*}{ Participants } & \multicolumn{2}{|c|}{ Cognitive impairment } \\
\hline & & & & $\mathrm{HR}(95 \% \mathrm{Cl})$ & $P$ value \\
\hline \multirow[t]{4}{*}{ Model $1^{a}$} & Underweight & 1323 & 4074 & $1.55(1.44,1.67)$ & $<0.001$ \\
\hline & Normal & 1464 & 6181 & Reference & - \\
\hline & Overweight & 224 & 1370 & $0.63(0.55,0.73)$ & $<0.001$ \\
\hline & Obese & 75 & 402 & $0.77(0.61,0.97)$ & 0.025 \\
\hline \multirow[t]{4}{*}{ Model $2^{b}$} & Underweight & 1323 & 4074 & $1.05(0.98,1.14)$ & 0.177 \\
\hline & Normal & 1464 & 6181 & Reference & - \\
\hline & Overweight & 224 & 1370 & $0.84(0.73,0.96)$ & 0.013 \\
\hline & Obese & 75 & 402 & $1.01(0.80,1.27)$ & 0.937 \\
\hline \multirow[t]{4}{*}{ Model $3^{c}$} & Underweight & 1323 & 4074 & $1.02(0.94,1.10)$ & 0.648 \\
\hline & Normal & 1464 & 6181 & Reference & - \\
\hline & Overweight & 224 & 1370 & $0.86(0.75,0.99)$ & 0.036 \\
\hline & Obese & 75 & 402 & $1.01(0.80,1.28)$ & 0.906 \\
\hline
\end{tabular}

Note: BMI: body mass index; HR: hazard ratio; Cl: confidence interval; Baseline BMI was classified as underweight $\left(\mathrm{BMl}<18.5 \mathrm{~kg} / \mathrm{m}^{2}\right)$, normal $\left(18.5 \leq \mathrm{BMl}<24.0 \mathrm{~kg} / \mathrm{m}^{2}\right)$, overweight $\left(24.0 \leq \mathrm{BMl}<28.0 \mathrm{~kg} / \mathrm{m}^{2}\right)$ and obesity $\left(\mathrm{BMI} \geq 28 \mathrm{~kg} / \mathrm{m}^{2}\right)$.

a: Univariable analysis

b: Age and sex were adjusted

c: Type of residence, marital status, education, living arrangement, smoking status, drinking status, regular exercise, vegetables and fruit intake were additionally adjusted.

Table 3. The association between BMI change and the incidence of cognitive impairment. 


\begin{tabular}{|c|c|c|c|c|c|}
\hline \multirow[b]{2}{*}{ Model } & \multirow[b]{2}{*}{ Categorical } & \multirow[b]{2}{*}{ Events } & \multirow[b]{2}{*}{ Participants } & \multicolumn{2}{|c|}{ Cognitive impairment } \\
\hline & & & & $\mathrm{HR}(95 \% \mathrm{Cl})$ & $P$ value \\
\hline \multirow[t]{5}{*}{ Model $1^{a}$} & Large weight loss & 966 & 2912 & $1.77(1.61,1.95)$ & $<0.001$ \\
\hline & Small weight loss & 325 & 1511 & $1.01(0.89,1.15)$ & 0.834 \\
\hline & Stable weight status & 783 & 3592 & Reference & - \\
\hline & Small weight gain & 266 & 1186 & $1.04(0.90,1.19)$ & 0.587 \\
\hline & Large weight gain & 746 & 2826 & $1.29(1.16,1.42)$ & $<0.001$ \\
\hline \multirow[t]{5}{*}{ Model $2^{b}$} & Large weight loss & 966 & 2912 & $1.38(1.26,1.52)$ & $<0.001$ \\
\hline & Small weight loss & 325 & 1511 & $1.00(0.88,1.14)$ & 1 \\
\hline & Stable weight status & 783 & 3592 & Reference & - \\
\hline & Small weight gain & 266 & 1186 & $1.09(0.94,1.25)$ & 0.249 \\
\hline & Large weight gain & 966 & 2912 & $1.38(1.26,1.52)$ & 0.073 \\
\hline \multirow[t]{5}{*}{ Model $3^{c}$} & Large weight loss & 966 & 2912 & $1.42(1.29,1.56)$ & $<0.001$ \\
\hline & Small weight loss & 325 & 1511 & $1.01(0.89,1.15)$ & 0.909 \\
\hline & Stable weight status & 783 & 3592 & Reference & - \\
\hline & Small weight gain & 266 & 1186 & $1.08(0.94,1.24)$ & 0.312 \\
\hline & Large weight gain & 746 & 2826 & $1.04(0.94,1.16)$ & 0.414 \\
\hline
\end{tabular}

Note: BMI: body mass index; HR: hazard ratio; Cl: confidence interval; BMI change was classified as large weight loss (BMI change $<-10 \%)$, small weight loss $(-10 \% \leq \mathrm{BMI}$ change $<-5 \%)$, stable weight status $(-5 \% \leq$ $\mathrm{BMI}$ change $<5 \%$ ), small weight gain $(5 \% \leq \mathrm{BMI}$ change $<10 \%)$ and large weight gain (BMI change $>10 \%)$.

a: Univariable analysis

b: Age and sex were adjusted

c: Type of residence, marital status, education, living arrangement, smoking status, drinking status, regular exercise, vegetables, fruit intake and baseline BMI group were additionally adjusted.

\section{Figures}




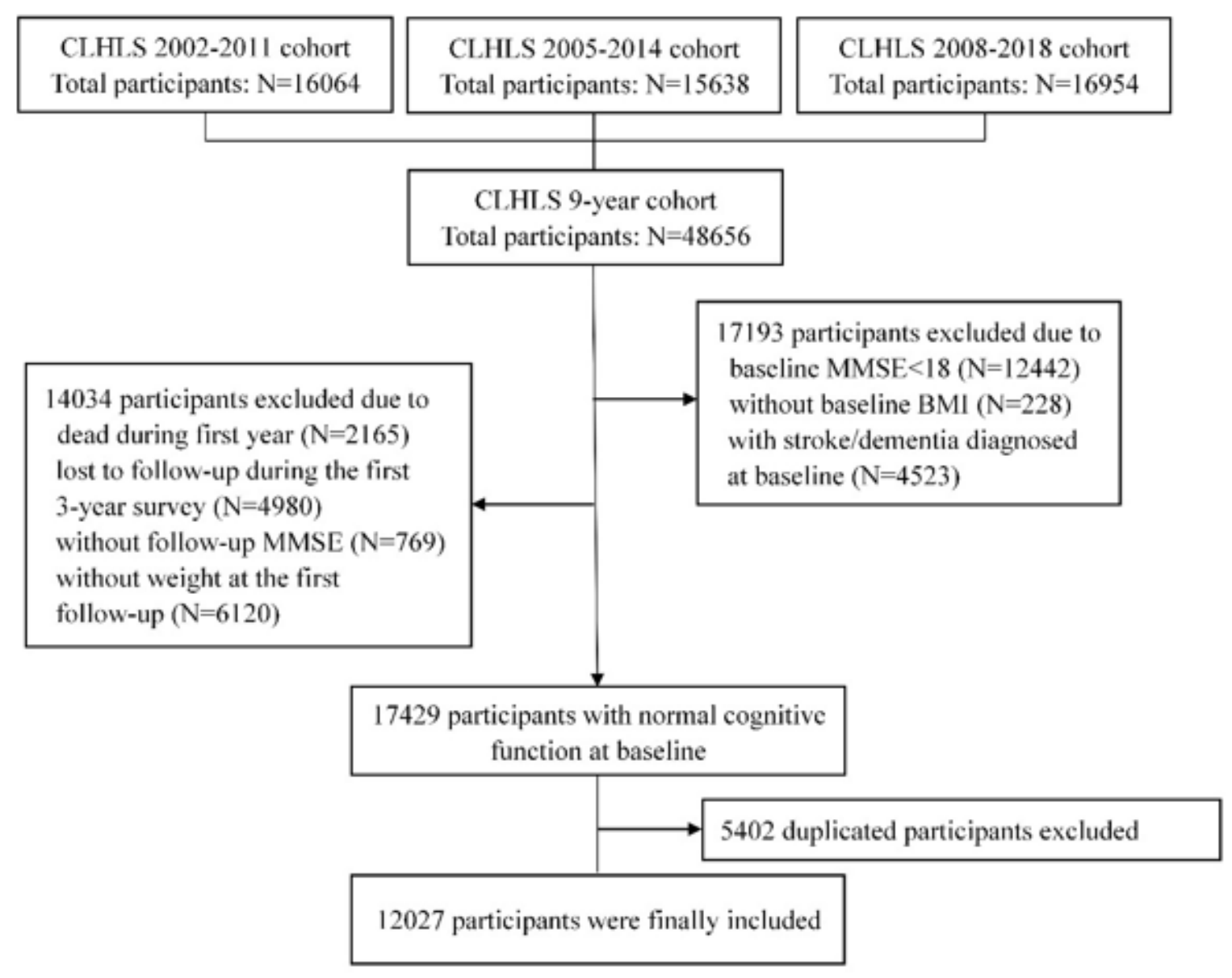

Figure 1

Flow chart of the study population. Note: CLHLS: Chinese Longitudinal Health Longevity Study.
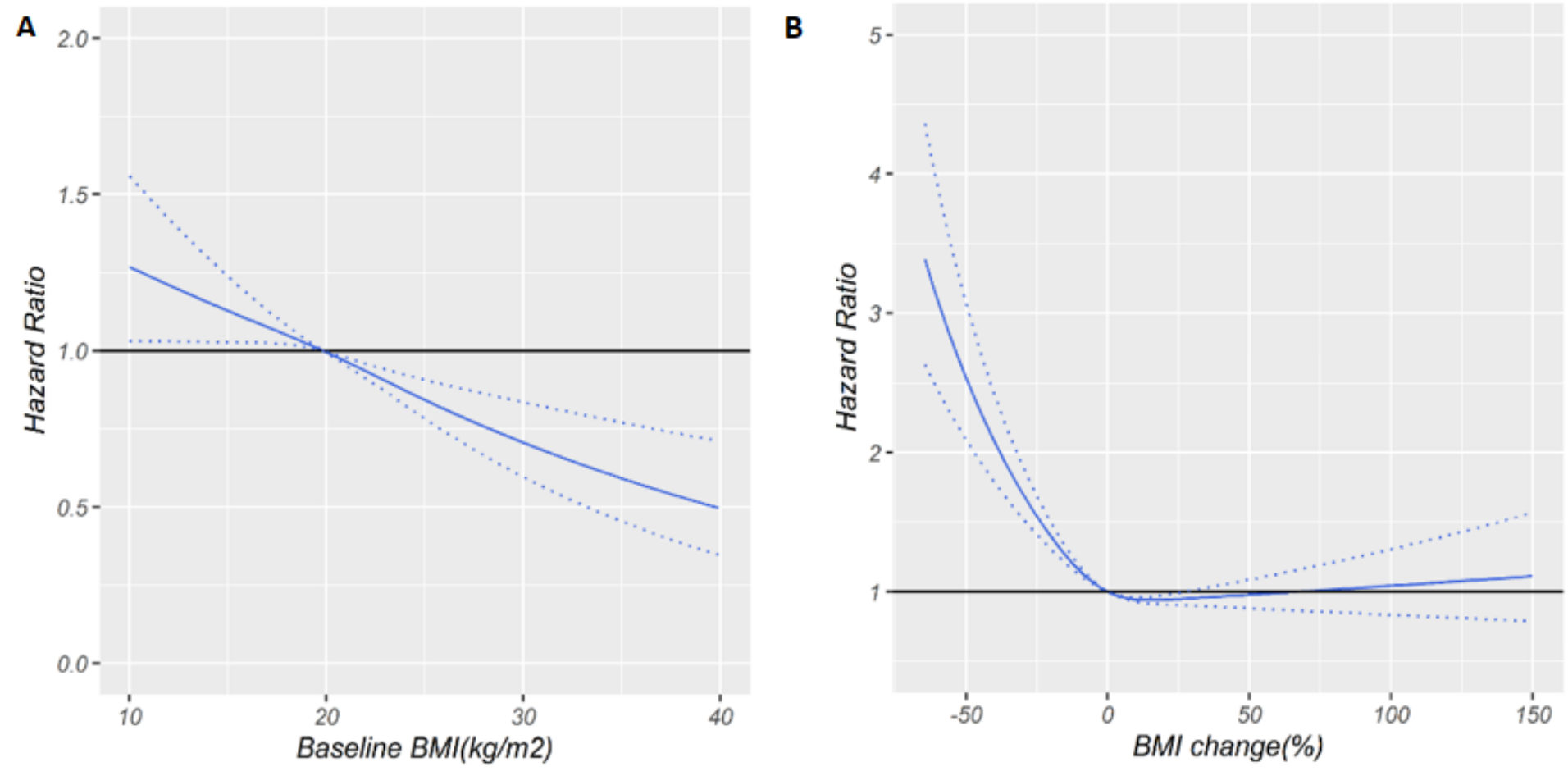


\section{Figure 2}

Restricted cubic spline for the association of baseline BMI and BMI change with cognitive impairment. A. Baseline BMI and cognitive impairment: reference point is the median value of baseline BMI $(19.84 \mathrm{~kg} / \mathrm{m} 2)$, after adjusting for age, sex, type of residence, marital status, education, living arrangement, smoking status, drinking status, regular exercise, vegetables and fruit intake. B. BMI change and cognitive impairment: reference point is the median value of $\mathrm{BMI}$ change $(0 \%)$, with knots placed at 10 th, 50th and 90 th percentiles, after adjusting for age, sex, type of residence, marital status, education, living arrangement, smoking status, drinking status, regular exercise, vegetables, fruit intake and baseline BMI. Note: Hazard ratios are indicated by solid lines and $95 \%$ confidence intervals by dashed lines, with knots placed at 10th, 50th and 90th percentiles. 


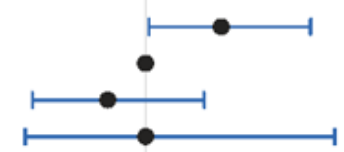

$\geq$ XII years

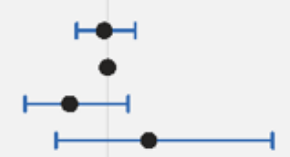

Ficmate

Underweight

Normal

Overweight

$\begin{array}{cc}997 & 2450 \\ 909 & 2991 \\ 134 & 650 \\ 46 & 214\end{array}$

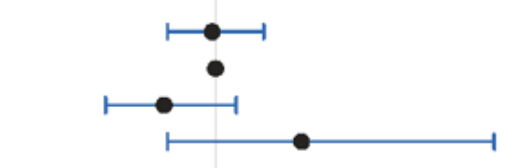

$0.99(0.86,1.14)$

Relerence

$0.85(0.68,1.06)$

$1.25(0.86,1.81)$

Obese

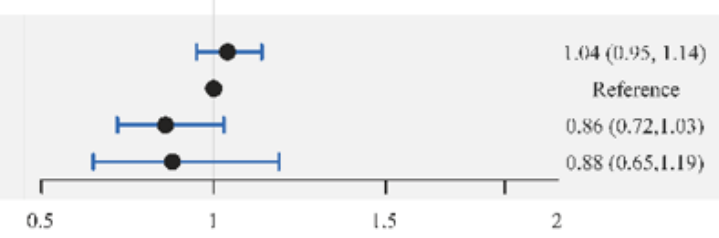

BMI change

Events Participants

Adjusted $\mathrm{HR}(95 \% \mathrm{Cl})$

\section{Age}

65-79 years

Large weight loss Small weight loss

Stable weight status

Small weight gain

I arge weight gain

$\geq 80$ years

Large weight loss

Small weight loss

Stable weight status

Small weight gain

I arge weight gain

\section{Gender}

Male

Large woight loss Small weight lass

Stable weight status

Small weight gain

Large weight gain

Female

Large weight loss Small weight loss Stable weight status Small weight gain Large weight gain

$\begin{array}{cc}135 & 10 \\ 55 & 725 \\ 161 & 18 \\ 53 & 61 \\ 138 & 117 \\ 831 & 18 \\ 270 & 7569 \\ 622 & 17 \\ 213 & 579 \\ 6018 & 164\end{array}$

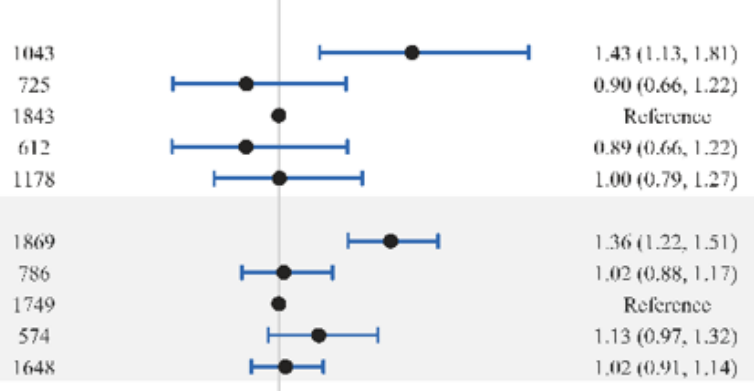

\section{Figure 3}

Subgroup analysis for the association of baseline BMI and BMI change with cognitive impairment. A. Subgroup analysis by age and gender for baseline BMI; B. Subgroup analysis by age and gender for BMI change. Note: BMI: body mass index; HR: hazard ratio; Cl: confidence interval. Adjusted covariates include age, sex, education background, marital status, smoking status, alcohol drinking, fruit intake, vegetables intake, type of residence, regular exercise and living arrangement. Baseline BMI group was additionally adjusted for results of BMI change. Baseline BMI was classified as underweight (BMI $<18.5 \mathrm{~kg} / \mathrm{m} 2)$, normal 
(18.5 $\leq \mathrm{BMI}<24.0 \mathrm{~kg} / \mathrm{m} 2)$, overweight $(24.0 \leq \mathrm{BMI}<28.0 \mathrm{~kg} / \mathrm{m} 2)$ and obesity $(\mathrm{BMI} \geq 28 \mathrm{~kg} / \mathrm{m} 2)$; BMl change was classified as large weight loss (BMI change $<-10 \%)$, small weight loss $(-10 \% \leq \mathrm{BMI}$ change $<-5 \%$ ), stable weight status $(-5 \% \leq \mathrm{BMI}$ change $<5 \%)$, small weight gain $(5 \% \leq \mathrm{BMI}$ change $<10 \%)$ and large weight gain (BMl change $>10 \%$ ).

\section{Supplementary Files}

This is a list of supplementary files associated with this preprint. Click to download.

- SupplementaryMaterials.docx 